\title{
Conceptual basis of mining intensification by the geomechanical factor
}

\author{
Serhii Skipochka, ${ }^{1, *}$ \\ ${ }^{1}$ Institute of Geotechnical Mechanics named by N. Poljakov of National Academy of Sciences of \\ Ukraine, 49005, Dnipro, Simferopolska Str., 2a, Ukraine
}

\begin{abstract}
The goal of the work was to develop a concept of intensification of mining operations, taking into account geomechanical processes occurring in the "rock massif - mining workings - support and protective structures" system. The article is the result of theoretical and experimental research materials analysis and synthesis, carried out for the conditions of coal, non-metallic and iron-ore mines. Positive and negative geomechanical processes and phenomena, occurring during intensification of mining operations, have been substantiated. A set of technical and technological solutions to eliminate the negative phenomena associated with high mining rates development of mineral resources has been proposed. Recommendations, presented in this article, will significantly reduce the conditionally fixed costs of mining production and improve miner's safety.
\end{abstract}

\section{Introduction}

The intensity of any industrial production is determined by a number of objective and subjective factors, including qualifications of the managerial and production personnel, organizational aspects, equipment, atmosphere and stimulation of the team, etc. Another significant aspect in the field of mining is the natural factor. First of all, these are geological features of the field and geomechanics of the behavior of the rock massif, as well as its interactions with the workings, support and protective structures during the development of the field. The influence of the geomechanical factor is especially noticeable in coal mines.

The basis of the stated concepts of intensification of mining operations, taking into account geomechanical features of the rock massif and its interaction with support and protective structures, are the results of theoretical and experimental studies carried out for the conditions of the development of coal, non-metallic (shallow mines) and iron ore deposits of Ukraine. Since geomechanics of the behavior of an array of coal, ore, and nonmetallic deposits differ significantly, the concepts of intensifying mining operations for each type of deposits are considered separately.

It should be noted that in Ukraine solid mineral deposits are characterized by complex mountain and geological conditions. However, this does not exclude the possibility of using the proposed concept in other, more favorable conditions.

*Corresponding author: skipochka@ukr.net 


\section{Methods}

We used the methods of analysis and synthesis of scientific and practical results obtained by the author or with his participation in performing theoretical (analytics and mathematical modeling) and experimental (physical modeling, mining observations, mechanical and geophysical measurements) studies [1-3]. The object of experimental research is the coal mines of Western Donbas, the gypsum mine (Bakhmut), iron ore mines (Zhovti Vody, Kryvyi Rih, Dniprorudnyi).

\section{Results and discussion}

\subsection{The concept of intensifying the work of coal mines on the geomechanical factor}

The functional diagram of the interrelation of the main factors influencing the intensity of the coal mine operation is shown in Figure 1.

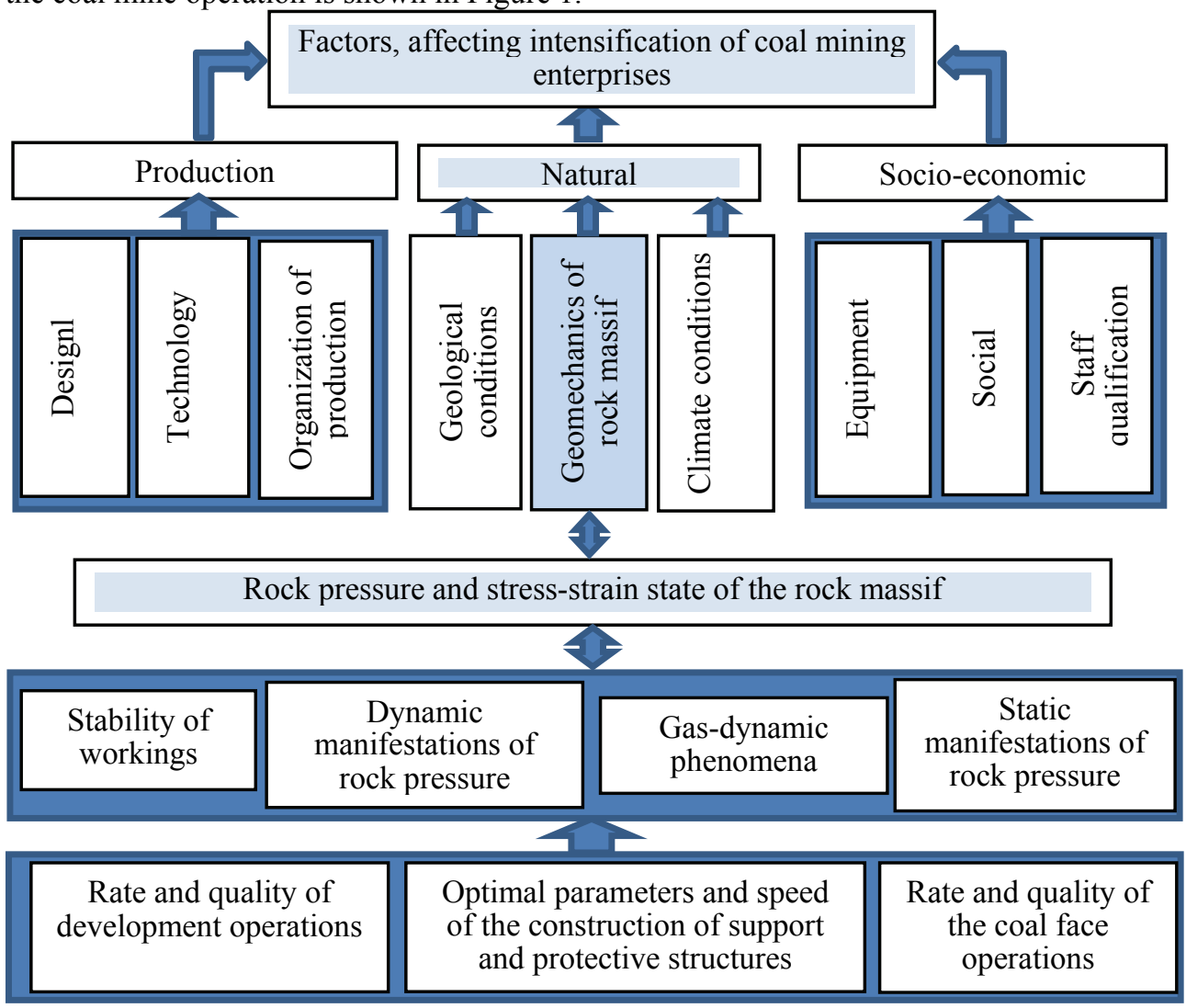

Fig. 1. Factors, affecting intensification of coal mining, and their interrelation.

Analyzing the long-term experience of the industry, it is very likely that the intensity of coal mining is mainly influenced by three factors: production, natural and socio-economic. Moreover, the degree of influence of these factors is approximately equivalent. That is, by eliminating or reducing the degree of influence of one of them, in our case, geomechanical, it is possible to increase the volume of production by $20-30 \%$, reduce the cost of 
production and the level of industrial injuries.

It is known that intensification of coal mining is determined, first of all, by the rate and quality of development workings, as well as by the speed of cleaning operations. Both of these factors are closely related to geomechanics of the coal and rock massif. For example, the analysis and generalization of the results of experimental and theoretical studies [4] made it possible to describe the mechanism of stress-strain state formation for the unstable rock mass at high rates of surface exposure in the following way.

When the speed of cleaning operations increases, the length of the main roof console, hanging over the developed part of lava increases and rests in width on the powered support structure and the mass area, located along the line of the clearing face, and on the edges along the length of support and protective structures of the drift. There are two reasons for the main roof console length increase and an associated step of roof collapse. Firstly, it is a delay in processes of relaxation of stresses and deformations. Secondly, it is an increase in the strength of rocks and their acquisition of subtle properties due to an increase in the loading rate of edge parts of the rock massif.

An increase in the length of the main roof console leads to an increase in pressure on the powered support structure, especially its back stand, and the marginal part of the coal seam. This increases the concentration of stresses in the marginal part of the coal seam, which provokes an increase in the stress dissipation zone and the values of tensile stresses in the soil in the area of the projection of the stop line. The combined effect of tensile stresses and pressure on the soil by mechanized face support structures leads to heaving and tearing of the portion of the soil located between the lining and the line of the breakage face, which is illustrated in Figure 2a.

Several other processes occur in the marginal part of the main roof console, supported by drifts and their protective structures. Increasing the length of the console leads to a proportional increase in pressure on the drift support. Moreover, the main negative changes occur in the area of the drift section, adjacent to the existing coal face (Fig. 2b).

Significant but positive changes occur in the mine working bottom. If we imagine the mechanism of bottom swelling in the drift as a result of the joint action of the process of releasing potential energy and tangential stress components in the berm part of the drift, then, due to the mismatch between the exposure times of the array and relaxation processes, as well as the lack of pressure on the berm part of the drift and tensile stresses from the side of lava, the bottom swelling in the drift decreases with increasing speed of the movement of the coal face.

In practice, these processes lead to a number of both negative and positive phenomena. In particular, negative phenomena include:

- the formation of an additional zone of high stresses up to $2.0 \gamma H$ (where: $\gamma-$ overburden density, $H$ - reservoir depth) in the rock massif, parallel to the total length of faces;

- an increase in pressure in the hydraulic system of powered support structures up to $350-400 \mathrm{kN} / \mathrm{m}^{2}$;

- an increase in the step of roof caving $l_{c}$ to $25-30 \mathrm{~m}$ and more;

- 2.0-2.5 times increase in pressure on the liner and 1.5 times convergence of rocks in the drift at the lava-drift interface.

Positive processes include:

- reduction of the zone of influence of face on drifts from 100-120 m to 70-90 m;

- reduction of the required quantity of soil bottom undermining in the drift from threefour to two;

- a decrease in spacing of step of roof collapse is inversely proportional to the speed of movement of face. 


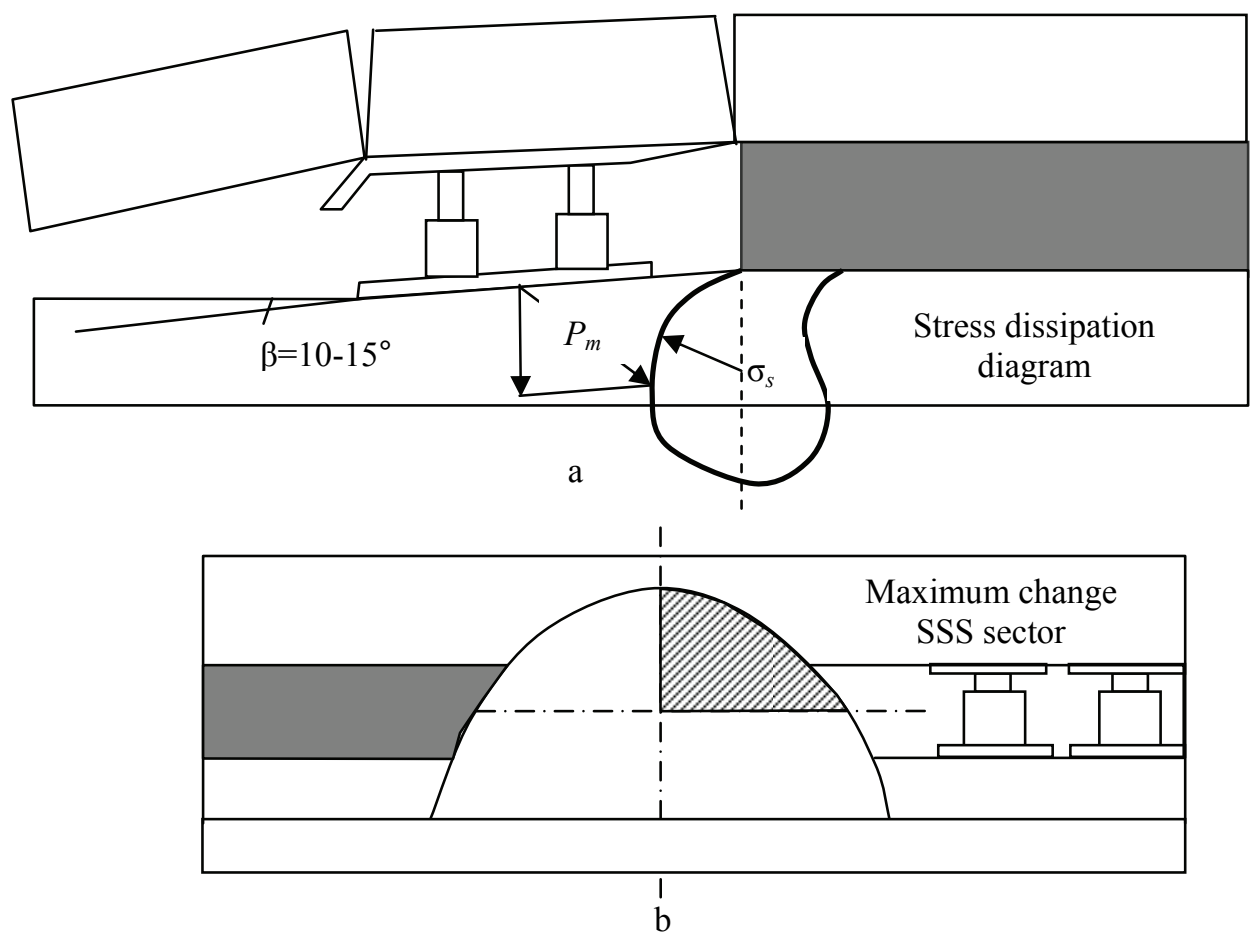

Fig. 2. Schemes of stress-strain state (SSS) formation mechanism in the coal-rock massif.

Thus, optimizing the influence of geomechanical processes while increasing the speed of cleaning operations should be aimed at reducing the spacing of roof breaks to traditional values or adapting power parameters of face and drift support structures, especially at the lava - drift interface, to new conditions.

Theoretically, the improvement of the geomechanical situation in lavas at high speeds of cleaning operations can be achieved in two ways. Firstly, by reducing the influence of the main roof console, hanging over the developed part of lava, which simultaneously improves the conditions for maintaining drifs, and secondly, by increasing the working resistance of mechanized face support structures.

The first way can be implemented by a forced collapse of the roof with a given pitch; by laying rubble strips perpendicular to the line of the working face; by laying bonfire parallel to the working face; or by using a special technological cycle of mining, which reduces the pitch of the main roof.

In all cases, it is necessary to be guided by the economic feasibility of carrying out certain technological measures. It should be kept in mind that increasing the load on the working face, for example, by $10 \%$, provides for a reduction of semi-fixed costs by $\$ 40,000-100,000$.

In some cases, by increasing the load on the working face, the problem of maintaining drifts in a satisfactory condition is solved without the involvement of any unconventional technology. The normal geomechanical working conditions of lava can be ensured by changing power characteristics of the mechanized support structures, for example, by redistributing the pressure in hydraulic systems of front and rear pillars, increasing the pressure in the rear pillar by $15-20 \%$. Such a solution will ensure the leveling of the support structures and will increase its bearing capacity. In addition, it will reduce the pressure component that provokes the swelling of soil rocks in lava.

The concept of intensifying coal mining necessarily implies a tandem solution. On the 
one hand, this is increase of the load face, on the other hand, a timely and sufficient amount of preparatory work, i.e., carrying out and maintaining mine workings in a condition suitable for exploitation.

From the point of view of geomechanics, this issue can be resolved by optimizing (with justification of economic feasibility and safety) the two most acceptable options: carrying out local drifts and their maintenance using the technology of roof-bolt-fastening, with the subsequent caving of drifts; or making and fixing workings according to the traditional technology of frame-arched support with repeated use of drifts when working on the neighboring lava.

Referring to the second option, it should be noted that protection of the drifts for the purpose of their reuse can be provided even in unstable rocks, but if one of the following conditions is met:

- the compulsory construction of the protective structure in the lava zone with a width of 2.0-2.5 m from a material with a tensile strength and temporary compressive strength $R_{c}$ $10-15 \mathrm{MPa}$, elastic modulus $E$ not less than $10^{3} \mathrm{MPa}$, however, the size of the berm should not be less than the height of undermining of the seam;

- the creation of conditions for the collapse of roof rocks on the edge of the "drift - lava" at an angle of at least $80^{\circ}$ to the horizon.

However, increasing the speed of cleaning operations, the pressure on the drift and its support and protective structures increases significantly, which requires changing their parameters. The calculations showed, that drifts, for the lava movement speed more than 8-10 $\mathrm{m} /$ day, can be preserved for their reuse required the construction of a protective strip with $E \geq 10^{4} \mathrm{MPa}$ and $R_{c} \geq 20 \mathrm{MPa}$, i.e. based on concrete mixtures, the time of construction and curing of which do not meet the requirements of the face traversing speed. For these reasons, at the mines, in the Western Donbas region, which use intensive technologies, cross pitch entries are extinguished following the passage of lava. In some mines in the Central Donbas region, for example, the company "Pokrovskoe", uses protective cast strips. The geomechanical conditions of use of the cast strip, the technological features of its construction, and the method and sequence of calculations have been studied and described in [4-6].

Depending on the distance from drift to the strip $a$, the size of bedrock disruption $d$ and the strip shape factor $K_{f}$, it is recommended to use three designs of protective strips. For easily destroyed roofs the width should be $0.7 \mathrm{~m}, R_{c}>40 \mathrm{MPa}, a=d, K_{f}=0.8$; for moderately destroyed roofs - width $1.0 \mathrm{~m}, R_{c}>40 \mathrm{MPa}, a=d, K_{f}=0.8$; for hard roofs width $1.2 \mathrm{~m}, R_{c}>40 \mathrm{MPa}, a=0.6 d, K_{f}=1.2$.

It is known that the pressure on the support drift is determined mainly by three factors: the depth development, the size of the area of inelastic deformations and the magnitude of the additional load due to the influence of the main roof console hanging over the developed part of lava. Since the speed of movement of lava affects only the third factor, it is advisable to justify the ways to strengthen the drift support structures and their parameters based on the values of the load obtained experimentally, as well as data from analytical calculations. For example, the technology of mining in the Western Donbas region provides for the removal of conveyor drives to the drift and, accordingly, the removal of the stands of two or three sections of arch support structure in the process of moving the complex. Therefore, reinforcement support should not only counteract the load from the rock console, but also maintain the arch support for the period of removal of the stand. This can be achieved by improving the way of connecting elements of support structures and filling the mounting space; by improving the elements of frames and dumming, or by constructing rock bolts in length from 1.8 to 2.5 meters. At lava-drift interface drift support reinforcement can be achieved by improving the elements for grabbing the top of support structures; by using the mechanized support; or by using rock 
bolts for hardening the roof of the seam in the zone of interfacing and fastening of the upper slabs of roofing support structures.

Optimally, such requirements can be met by the scheme of intensifying the upper arch with rock bolts in the direction of the developed lava at an angle of about $60^{\circ}$. This allows "to use" rock massif, to ensure the stability of lava-drift interface when removing the support stand, and to ensure maintenance-free of drifts during the entire service life.

In terms of importance, the most significant impact on coal mining processes is exerted by five main parameters, the magnitude of which is determined by the rate of array exposure. They are pressure change $P_{m r}$ on mechanized lava support; pressure change on drift support; an increase in swelling in the heaving of soil rocks in the drift, characterized by the quantity of undermining operations, necessary for ensuring technological processes; the change in pressure on the face end support; increase in layer bedrock swelling in face in the area from the bottom line to the mechanized support.

Each of these parameters should be considered separately. In some cases, you can, for example, use the graphical material presented in Figure 3, obtained for the conditions of the mines of the Western Donbas region.

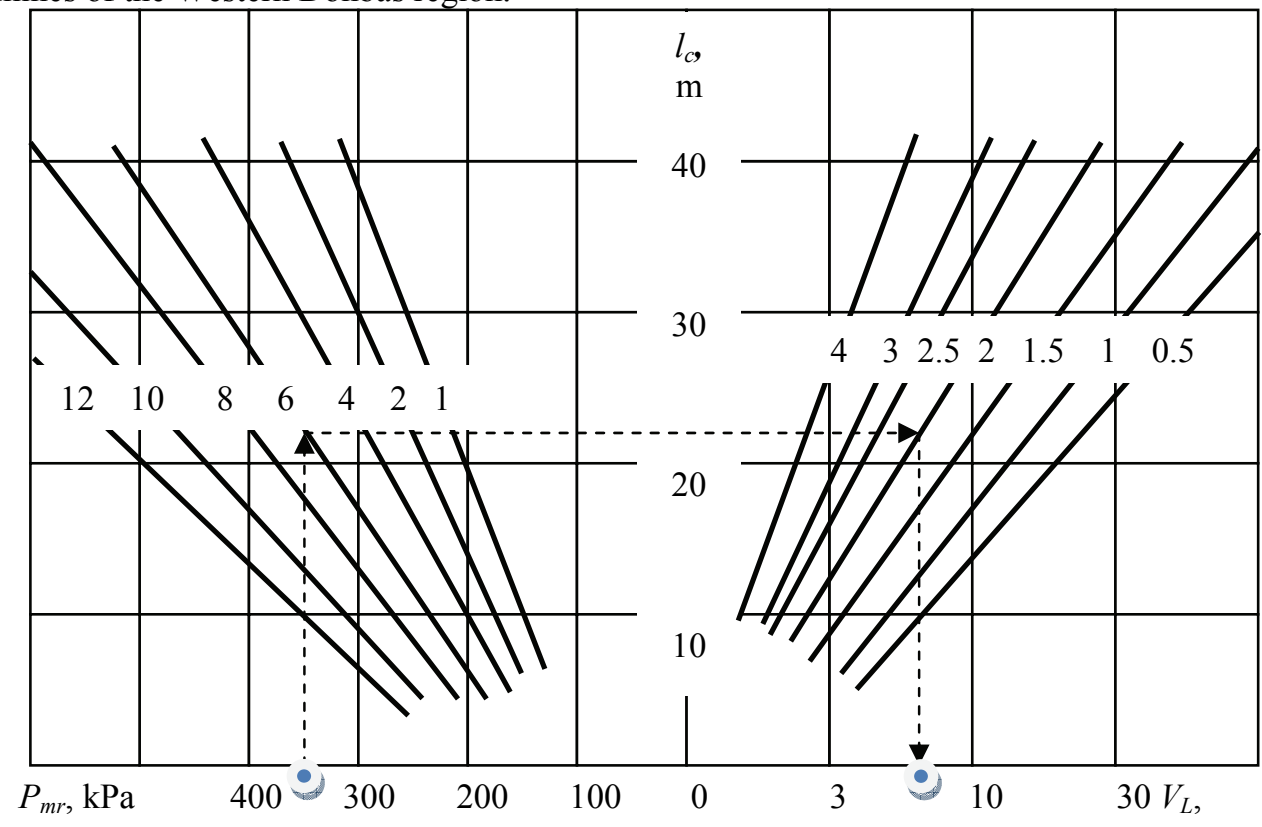

Fig. 3. Nomogram for determining the maximum speed of the movement of lava according to the criterion "pressure on the mechanized lava support" at different values of the main roof thickness $m_{r}, \mathrm{~m}$ (left quadrant) and the tensile strength of roof rocks $\sigma_{s}, \mathrm{MPa}$ (right quadrant).

To do this, from a point on the x-axis, corresponding to the resistance value of the mechanized roof support, a perpendicular line corresponding to the roof seam thickness is drawn. From the intersection point, the horizontal line is drawn to the intersection with one of the lines corresponding to the tensile strength of roof rocks. From the last intersection point, a perpendicular to the right abscissa axis is drawn to determine the maximal speed of lava movement by the factor - the resistance of mechanized lava support. This procedure can be performed in the reverse order, if there is a need to determine the required mechanized lava support resistance value for a given speed of face movement.

Knowing the maximum face traversing speed, the load on the clearing face can be calculated and, if it turns out that the calculated limit load on the clearing face is lower than the required load, increase the working resistance of the mechanized support or the design 
length of lava.

When justifying the parameters of support linking should be guided by the results of research obtained in [7]. For reliable maintenance of the roof at the lava drift interface, it is recommended to use the powered support with a total resistance of more than $1200 \mathrm{kN}$; the use of advanced, and in the case of mining lava by a direct course - and lagging support in the area of $15-20 \mathrm{~m}$ from the mate (from the calculation - one stand on the frame); or additional fastening during the excavation of drifts (or 100-120 m from the area of cleaning operations) of the upper arch on the face of the extraction with rock bolts.

With an increase in the rate of movement of the working face, there is intensification of processes of rock swelling in lava. This can be decreased by reducing the length of the rock console by increasing the length of lava. Another solution is to change the design characteristics of mechanized supports by increasing the size of their base to overlap the surface of soil in the swelling area.

\subsection{The concept of intensification of ore and non-metallic mine operations}

The structure of factors affecting the intensification of mining enterprises of ore and nonmetallic industries, in general, is slightly different from the structure shown in Figure 1 for coal mines. However, regarding the geomechanical factor, there are a number of significant differences in operations of such enterprises.

Iron ore mines and the enterprises that extract uranium-containing ores in Ukraine are characterized by a rather large depth of development and high strength of both ores and host rocks. As a rule, the workings in such mines are supported selectively with the use of rod-shaped reinforced concrete lining or, in exceptional cases (in areas of tectonics, high fracturing and watering), with frame metal support.

The main geomechanical problems in these mines are: dynamic manifestations of rock pressure in the form of rock bump shock, loss of stability of the chambers and their sides, collapse of natural or artificial roofing (in the case of using the technology of layered excavation with laying). Another geomechanical problem is the presence or formation of stabbings and delaminations in the roof and the hanging side of the workings during mine operation.

Intensification of mining in ore mines is mainly done by the development of new technological schemes for mining with increased parameters of workings; the reduction of consumption of expensive cement when using backfilling; and the mechanization and automation of production processes.

At the same time, in order to increase the extraction rate of the mineral and reduce its cost, the minimum values from the range of the possible influence of the stress-strain state are included in the calculations of pillars, chambers, protective ceilings and filling materials.

Ore mines operations in the last two decades have shown that such an approach is expedient only from the point of view of economic indicators, but is not justified in terms of environmental and labor safety at the enterprises. Proof of this can be: the frequent cases of destruction of protective ceilings with subsidence of the earth's surface, positive dynamics of rock bursts, collapse and dumping in workings, leading to accidents.

Concerning the intensification of non-metallic mines (from the experience of the Bakhmut gypsum mine, the company "Siniat") it should be noted that, despite the difference in the used development systems, the technological solutions applied there to increase the volumes of raw material extraction and reduce its costs, in many ways coincide with the solutions for iron ore and uranium mines. The difference lies in the small depth of the development of the field, which under adverse conditions can cause the collapse of the earth's surface. 


\section{Conclusions}

Thus, a brief concept of the intensification of coal mining by the geomechanical factor is formulated as follows.

As in the case of taking into account production, socio-economic and other factors, the adaptation of technical and technological conditions of coal mining to geomechanical processes in the coal-rock mass should be carried out by searching for optimal solutions based on three main criteria (in order of importance). They are: mining safety, cost of coal mining, and labor productivity (production volumes per unit of time).

The main way to intensify coal mining is to increase the load on the face with timely and sufficient preparatory work. This is achieved by increasing the speed of cleaning works (outcrop of rock massif the array). An increase in the outcropping speed leads to a significant change in the geomechanical processes in the rock massif. When the speed of the movement of lava is more than $8 \mathrm{~m} /$ day, it is necessary to adjust technical and technological parameters of the mechanized complex of the lava, support structures, and security of mine workings, especially the lava-drift interface.

The main negative geomechanical factor at high face traversing speed is an increase in spacing of the main roof breaks. Technical and technological solutions should be aimed at reducing it to the optimal size about $20 \mathrm{~m}$. Another way is to create sufficient resistance to the lava and drift support structures (especially at lava - drift interface), as well as constructing special security structures in the wing part of the junction. Ways to solve this problem are justified on the basis of optimization conditions. They may include technical and technological solutions such as: increasing the length of lava, using unfixed mine work hours, forced collapse of the roof console, strengthening the lava and drift support, using reinforced interface of lava with drift support systems, organizing the system of geomechanical monitoring of mine workings, etc.

The concept of intensifying the work of ore mines taking into account the geomechanical factor can be formulated as follows.

The direction of intensification of production chosen by ore enterprises through the improvement of technological excavation schemes with increased parameters of clearing workings and the minimum possible parameters of security parts of the mass is correct. However, it almost does not take into account the influence of the geomechanical factor. This can lead to the decrease in the main criterion - miners work safety. Therefore, the introduction of such a technological solution must be supplemented by the following conditions. To eliminate errors, calculations of technological parameters of the clearing excavation should be carried out by two design organizations, preferably by different methods and with mandatory modeling of critical states. The operation of objects with boundary values of parameters is possible only under the condition of constant, systemic and multiparameter monitoring of properties and stress-strain state of the rock mass by organoleptic methods and methods of non-destructive testing.

The basis of such monitoring may be the developments outlined in the work [8].

The concept of intensifying the operation of non-metallic mines according to the geomechanical factor must be supplemented by a provision on mandatory regular organoleptic control of the roof of workings, systematic non-destructive control of dangerous parts of the roof and support structures, as well as equipping the dangerous parts of the roof with offset indicators signaling in cases of exceeding the value of standard parameters.

The results are part of the program "Promoting the development of priority research areas" of state funding for the National Academy of Sciences of Ukraine (Code of program classification of expenses and crediting 6541230). 


\section{References}

1. V.G. Chervatuk, The Model of Computing Experiment of Interplays in the System "Support - Rock mass" on Linkings of Mining Drifts. Geotechnological Issues of Underground Space Use for Environmentally Protected World 119-120 (2001)

2. Skipochka, S.I., Muhin, A.V., Kuklin, V.Yu. (2003). Osobennosti geomekhaniki ugleporodnogo massiva pri vysokikh nagruzkakh na ochistnoy zaboy, Geo-Technical Mechanic, 41, 16-22

3. Skipochka, S.I., Muhin, A.V., Kuklin, V.Yu. (2003). Geomekhanicheskie aspekty povedenija massiva plastovykh shtrekov pri vysokikh skorostyakh podviganiya lav, Problemy girskogo tysku, 9, 108-119

4. Skipochka, S.I., Usachenko, B.M., Kuklin, V.Yu. (2006). Elementy geomekhaniki pri vysokikh skorostyakh podviganiya lav. Dnipropetrovsk: Lira Ltd

5. Baysarov, L.V., Ilyashov, M.A., Demchenko, A.I. (2005). Geomekhanika $i$ tekhnologiya podderzhaniya povtorno ispolzuemykh gornykh vyrabotok. Dnipropetrovsk: Lira Ltd

6. Bulat, A.F. (2006). Vremennyu tekhnologichnyu reglament po okhrane podgotovitelnykh vyrabotok ugolnykh shakht Ukrainy litymi polosami iz tverdeyushchykh materialov. Dnipropetrovsk: Dnepr-VAL

7. Skipochka, S.I., Mukhin, A.V., Chervatuk, V.G. (2002). Geomekhanika okhrany vyemochnykh shtrekov v neustoychivykh porodakh. Dnipropetrovsk: NGAU

8. Antsyuferov, A.V. (2010). Geomekhanichnyu monitoryng pidzemnykh geotekhnichnykh system. Donetsk: Noulidg 